Check for updates

Cite this: RSC Adv., 2018, 8, 1274

\title{
Amphoteric starch derivatives as reusable flocculant for heavy-metal removal $\uparrow$
}

\author{
Liang Wu, ${ }^{a}$ Xingrong Zhang, ${ }^{\mathrm{b}}$ Long Chen, ${ }^{a}$ Huan Zhang, ${ }^{a}$ Chengbi Li, ${ }^{\mathrm{b}}$ Yin LV, \\ Yisheng $\mathrm{Xu}^{\text {ac }}$ Xin Jia, (D) ${ }^{a}$ Yulin Shi ${ }^{\text {(D) }}{ }^{* a}$ and Xuhong Guo (D)*ac
}

A pH-responsive amphoteric starch derivative (PRAS) bearing dual functional groups (amino and carboxyl groups) was prepared through etherification of starch with 2-chloro-4,6-diglycino-[1,3,5]-triazine. PRAS exhibits a reversible $\mathrm{pH}$-response property in aqueous solution. The attractive property of PRAS is that it could be used as an effective flocculant for heavy metal-ion (e.g. Cu(॥) and $\mathrm{Zn}(I)$ ) removal from wastewater by changing $\mathrm{pH}$. The transition of hydrophobicity-hydrophilicity would produce shrinkage of the polymer matrix, facilitating the release of heavy-metal ions from the saturated flocculant. As an ideal flocculant PRAS displayed outstanding stability and reproducibility, whose remove rate for $\mathrm{Cu}(॥)$ and $\mathrm{Zn}(॥)$ remained at $93 \%$ and $91 \%$ after three flocculation/regeneration cycles.

Received 26th November 2017 Accepted 22nd December 2017

DOI: $10.1039 / c 7 r a 12798 g$

rsc.li/rsc-advances

overall processing and for opening the possibility of recovery

\section{Introduction}

Waste water containing heavy metals is often discharged by metal plating plants, mining smelting plants, and battery manufacturing plants, and has caused increasingly serious environmental problems. ${ }^{1-3}$ Zinc or copper is a trace element essential for human health, but excessive zinc or copper can trigger severe toxicological concerns and health problems. ${ }^{4-6}$

Adsorption and coagulation/flocculation processes have been extensively investigated to remove toxic heavy-metal ions from industrial effluents, and the latter has gained tremendous interest from industry due to their ability to enhance the formation of larger flocs and to promote solid-liquid separation of colloidal suspensions. ${ }^{7-9}$ Additionally, these flocculants have drawn particular attention as a water-soluble polymer due to their low cost (lower coagulant dose requirements), flexibility, simplicity, and easy operation. ${ }^{\mathbf{1 0}}$

The main disadvantage of flocculation with water-soluble polymers is the difficulty in regeneration and reusability after water treatment. ${ }^{\mathbf{1 1 , 1 2}}$ The flocculants characterized by both high removal efficiency and facile regeneration are expected in both fundamental and applicable studies. It is desirable to decoagulate the heavy-metal ions and to restore the flocculant to a state similar to its initial properties. The flocculant regeneration stage is very important for decreasing the costs of the

${ }^{a}$ Key Laboratory for Green Processing of Chemical Engineering of Xinjiang Bingtuan, School of Chemistry and Chemical Engineering, Shihezi University, Shihezi 832003, P. R. China.E-mail: shiyulin@shzu.edu.cn

${ }^{b}$ State Key Laboratory of Mineral Processing, Beijing 102628, China ${ }^{c}$ State Key Laboratory of Chemical Engineering, East China University of Science and Technology, Shanghai 200237, China.E-mail: guoxuhong@ecust.edu.cn

$\dagger$ Electronic supplementary information (ESI) available. See DOI: $10.1039 / \mathrm{c} 7 \mathrm{ra12798g}$ and further reuse of the heavy metals from the regenerated solution. However, the recovery of flocculant is challenging, and thus much less studied than the flocculation process. The difficulty of the recovery may due to the following reasons: (1) there exists high affinity between heavy metals and the flocculants including charge neutralization, polymer bridging, and electrostatic interactions. (2) Commercial flocculants are always highly soluble in water, and lack of controlled hydrophilelipophile balance on the polymer chain which makes it hard to separate flocculant from the regenerated solution.

Stimulus-responsive materials offer advantages for intelligent separation that switch their affinity for the target substance on and off in response to physical or chemical changes from the external environment. ${ }^{13-15}$ Compared to the traditional materials, the special hydrophobicity-controlled polymers show significant advantages in both separation rate and efficiency. Moreover, stimuli-responsive polymers enable straightforward recycling of solids for effective reuse with undiminished targetsubstance uptake and no physical change or damage. ${ }^{16}$ Taking this into account, Cao et al. developed a temperature and $\mathrm{pH}$ dual-responsive oil/water separation material that could be used for highly controllable oil/water separation processes. ${ }^{\mathbf{1 7}}$ This material enables quantitative capture and elution of oil by adjusting the temperature and $\mathrm{pH}$ without using organic solvents. Therefore, stimuli-responsive materials have high potential in water/oil separation. ${ }^{18}$

Traditional inorganic metal-based (polyaluminum chloride) and synthetic polymeric (polyacrylamide and its derivatives) flocculants are non-degradable, and directly discarding them after use will lead to secondary contamination of the environment. ${ }^{19}$ Over the last decade, environmentally friendly flocculants based on polysaccharides were developed. ${ }^{19-22}$ In our 


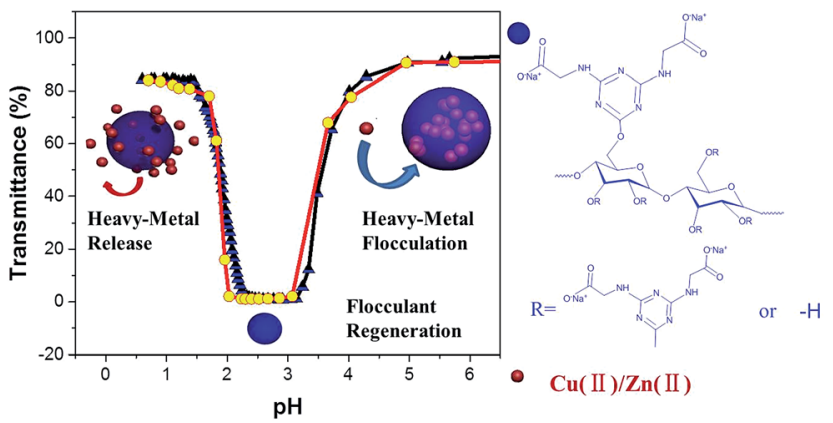

Scheme 1 (a) Schematic representation of the cyclic flocculation/ regeneration process; (b) molecular structure of the PRAS.

previous work, ${ }^{11,12}$ temperature- and/or $\mathrm{pH}$-responsive starch derivatives were used to build smart starch-based flocculants with reversible phase transitions in an aqueous solution. The as-prepared materials can remove dye from dyeing effluent with high efficiency and easy recyclability. Furthermore, the utilized starch-based flocculants can be easily decomposed because of their biodegradable and eco-friendly characteristics. ${ }^{9}$

In this work, a pH-responsive starch derivative containing both cationic and anionic functional groups was developed through etherification of starch with 2-chloro-4,6-diglycino$[1,3,5]$-triazine (CDT). The effects of the zwitterionic moiety and the hydrophobic moiety (s-triazine ring) on associative interactions were studied by utilizing turbidimetric titrations in aqueous media. The saturated flocculant based on $\mathrm{pH}$-responsive amphoteric starch (PRAS) can be facilely regenerated and separated from the solution by changing $\mathrm{pH}$ (Scheme 1). The transition of hydrophobicity-hydrophilicity can produce a shrinkage of the polymer matrix, facilitating the release of heavy-metal ions from the flocculant. The de-flocculation and reusability were also investigated in terms of the flocculation performance after several flocculation/desorption cycles.

\section{Experiment}

\subsection{Materials and reagents}

Raw maize starch (ST, purity $>98 \%$, w/w) was obtained from Heng-hui Food Co., Ltd. (Xinjiang, China). Cyanuric chloride (purity 99\%) was purchased from Tokyo Chemical Industry Co., Ltd. Glycine and ammonium hydroxide solution were obtained from Shanghai Tian Scientific Co., Ltd. Copper chloride $\left[\mathrm{CuCl}_{2} \cdot 2 \mathrm{H}_{2} \mathrm{O}\right]$ (purity 99\%) was provided by Fuchen Chemical Co., Ltd. (China). Zinc chloride $\left(\mathrm{ZnCl}_{2}\right)$ (purity 98\%) was obtained from Sinopharm Chemical Reagent Co., Ltd. (China). 2-Chloro4,6-diglycino-[1,3,5]-triazine (CDT) was conducted according to the literature. ${ }^{23}$ The synthesis route of CDT is depicted in the ESI (Scheme 1S $\dagger$ ). Distilled water was used throughout the entire flocculation/regeneration experiments. All the chemicals were used as-received without further purification.

\subsection{Preparation of pH-responsive amphoteric starch}

PRAS was prepared via an etherifying reaction between CDT and starch (ST) in dimethyl sulfoxide (DMSO). The synthesis of PRAS is shown in Fig. 1. Typically, ST ( $0.028 \mathrm{~mol}, 4.9 \mathrm{~g})$, solid sodium hydroxide (0.196 mol, $8.2 \mathrm{~g})$, CDT (0.084 mol, $22.0 \mathrm{~g})$, and DMSO were mixed in a four-necked flask under a $\mathrm{N}_{2}$ stream. The mixture was then heated to $80{ }^{\circ} \mathrm{C}$ and maintained at that temperature for $20 \mathrm{~min}$. Thereafter, the mixture was stirred at $130{ }^{\circ} \mathrm{C}$ for $10 \mathrm{~h}$ and then cooled to room temperature. Afterwards, three times the solution volume of methanol were added to the content of the flask, and the resulting precipitate was separated by filtration and then dried in a drying oven at $105^{\circ} \mathrm{C}$ for $10 \mathrm{~h}$. The product was purified by dialysis molecular weight cut-off (MWCO) 7000 Da against distilled water for $96 \mathrm{~h}$, followed by lyophilization. Then PRAS (DS $=0.17$ ) was obtained. Preparation method for the PRAS with the DS $=0.23$ is detailed in the ESI (Text S2†).

The degree of substitution (DS) of hydroxyl groups replaced by CDT groups can be calculated according to eqn (1), where the nitrogen amount $(N)$ is determined by elemental analysis. The determination of $\mathrm{C}, \mathrm{H}$ and $\mathrm{N}$ contents in PRAS were measured by German Element Vario EL III. Operating condition was oxidation furnace temperature $1150{ }^{\circ} \mathrm{C}$, reduction furnace temperature $850{ }^{\circ} \mathrm{C}$ and column temperature $110{ }^{\circ} \mathrm{C}$ under a $\mathrm{O}_{2}$ stream for $30 \mathrm{~min}$. The parameter 162 represents the molar quantity of the repeating unit in ST, and 226 is the molar quantity of CDT group residues on the carbohydrate side chains.

$$
\mathrm{DS}=\frac{162 \times N / 5}{1400-226 \times N / 5}
$$

\subsection{Characterization of PRAS}

Infrared spectra of ST and PRAS were recognized with a Fouriertransform infrared spectroscopy (FTIR) spectrometer (JASCO IR430 , Japan) within a wave number range of $400-4000 \mathrm{~cm}^{-1}$ at a resolution of $\pm 2 \mathrm{~cm}^{-1}$ by means of the $\mathrm{KBr}$ dispersion method. The samples were prepared by dry basis. ${ }^{1} \mathrm{H}$ nuclearmagnetic-resonance $\left({ }^{1} \mathrm{H}\right.$ NMR $)$ spectra were obtained using a $400 \mathrm{MHz}$ spectrometer (Varian INOVA 400, USA) after the 5$10 \mathrm{mg}$ purified samples were dissolved in $0.5 \mathrm{~mL}$ of $\mathrm{NaOD} / \mathrm{D}_{2} \mathrm{O}$. $\mathrm{C}, \mathrm{H}$, and $\mathrm{N}$ elemental analysis of PRAS was performed using an elemental analyzer (Vario EL, Germany). The zeta potential (ZP) was measured by a Micromeritics (USA) zeta/nanoparticle

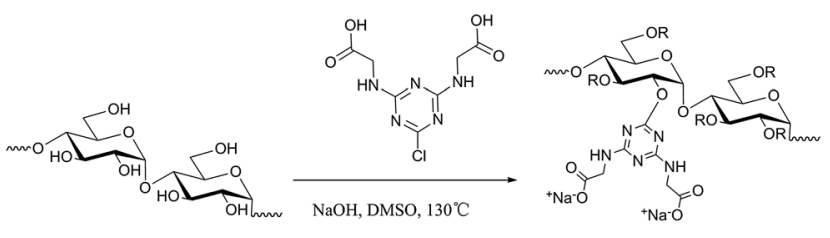

MS

PRAS

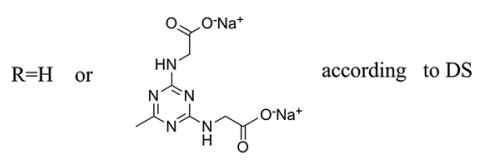

Fig. 1 Synthesis of PRAS by etherifying reaction. 
analyzer. In aqueous medium, a series of $2 \mathrm{~g} \mathrm{~L}^{-1}$ PRAS (DS $=0.23)$ solution with setting up $\mathrm{pH}$ values at room temperature were prepared. The samples were carried out by flow cell with $90^{\circ}$ optical source.

\section{4. $\mathrm{pH}$ responsiveness of PRAS}

The solution properties of PRAS were evaluated by turbidity measurements according to the literature. ${ }^{\text {24-26 }}$ PRAS (DS = 0.17 and 0.23 ) powder (500 $\mathrm{mg}$ ) was mixed with deionized water $(50 \mathrm{~mL})$, then, 5,10 , and $25 \mathrm{~mL}$ of $10 \mathrm{~g} \mathrm{~L}^{-1}$ PRAS solutions were pipetted into $50 \mathrm{~mL}$ water to prepare 1,2 , and $5 \mathrm{~g} \mathrm{~L}^{-1}$ PRAS solutions (initial $\mathrm{pH}$ value 8 ), respectively. The optical transmittance of the PRAS solution was determined at $590 \mathrm{~nm}$ using an ultraviolet-visible (UV-vis) spectrophotometer with a glass cell. The recovery curve was measured in two steps. Firstly, by dropwise adding $1 \mathrm{M} \mathrm{HCl}$ to $2 \mathrm{~g} \mathrm{~L}^{-1}$ PRAS (DS $=0.23$ ) solution and recording the corresponding change in the transmittance in the $\mathrm{pH}$ range $1.0-8.0$ at room temperature. Secondly, the transmittance change of PRAS solution was carried out in repeated cycles by adding $1 \mathrm{M} \mathrm{NaOH}$. Moreover, the $\mathrm{ZP}$ value of PRAS was measured under different $\mathrm{pH}$ conditions.

\subsection{Flocculation experiments}

In all metal flocculation experiments, standard jar tests were conducted at room temperature. Before each test, a $10 \mathrm{~g} \mathrm{~L}^{-1}$ PRAS stock solution was prepared by dissolving PRAS powder $(0.5 \mathrm{~g})$ in distilled water $(50 \mathrm{~mL})$.

$\mathrm{CuCl}_{2} \cdot 2 \mathrm{H}_{2} \mathrm{O}$ was dissolved in distilled water to yield a $3.9 \mathrm{~g} \mathrm{~L}^{-1} \mathrm{Cu}$ (II) stock solution and adjusted $\mathrm{pH}$ to 10.1 by $\mathrm{NH}_{3} \cdot \mathrm{H}_{2} \mathrm{O}$. The $\mathrm{Zn}$ (II) stock solution (3.7 $\mathrm{g} \mathrm{L}^{-1}, \mathrm{pH} 9.3$ ) was prepared and stored in the similar way. In a typical flocculation, distilled water $(9.0 \mathrm{~mL})$ and $0.2 \mathrm{~mL}$ of $\mathrm{Cu}(\mathrm{II})$ or $\mathrm{Zn}$ (II) stock solution were transferred into a centrifuge tube $(15 \mathrm{~mL})$. After a half hour, $0.05 \mathrm{~mL}$ PRAS stock solution was added to the simulative wastewater. Then the $\mathrm{pH}$ of the simulative wastewater was adjusted to the appropriate level by the addition of $1 \mathrm{M} \mathrm{HCl}$ or $\mathrm{NaOH}$, after which water was added to obtain a total volume of $10 \mathrm{~mL}$. In this system, the final concentrations of PRAS, $\mathrm{Cu}$ (II) and $\mathrm{Zn}$ (II) were 50, 78 and $74 \mathrm{mg} \mathrm{L}^{-1}$, respectively.

The jar test was repeated three times, corresponding results are analyzed with average values and std. deviation. ${ }^{27}$ The resulting mixture was shaken at (a) $150 \mathrm{rpm}$ for $2 \mathrm{~min}$, (b) $50 \mathrm{rpm}$ for $5 \mathrm{~min}$, and (c) $30 \mathrm{~min}$ of precipitate without stirring at room temperature by using constant temperature shaker (Blue Pard THZ-98A, China) according to the literature. ${ }^{10}$ Subsequently, the precipitate was kept still for $30 \mathrm{~min}$ to allow settling, and then the filtrate gathered by filtration using filter paper $(0.45 \mu \mathrm{m})$ for further residual concentration (RC) measurements. The appropriate dilution ratio was determined from preliminary tests and the RC of contaminants by using an atomic absorption spectrophotometer (AAS, Shimadzu AA-6300, Japan). All glassware was prepared by immersing it overnight in dilute $\mathrm{HNO}_{3}$, then washed by distilled water. Using an airacetylene flame as a flame atomizer, the height of burner and the air acetylene ratio were $8 \mathrm{~mm}$ and $6: 1$, respectively. Atomic absorption measurements were made at a hollow cathode lamp of $324.7(\mathrm{Cu})$ and $213.8(\mathrm{Zn}) \mathrm{nm}$. Determination of $\mathrm{Cu}(\mathrm{II})$ and $\mathrm{Zn}$ (II) in diluted filtrate by AAS.

The residual concentration of heavy metals was calculated from the calibration curve (Fig. S1†). Contaminant removal $(R \%)$ and the metal flocculation capacity were calculated from the following equations: ${ }^{28}$

$$
R=\frac{C_{0}-C_{\mathrm{f}}}{C_{0}} \times 100 \%
$$

where $C_{0}$ and $C_{\mathrm{f}}\left(\mathrm{mg} \mathrm{L}^{-1}\right)$ denote the initial and equilibrium contaminant concentration in the filtrate, respectively.

\subsection{Regeneration of PRAS}

To study the reusability of PRAS for removal of metal(II), $6 \mathrm{~mL}$ of $\mathrm{Zn}$ (II) or $\mathrm{Cu}$ (II) stock solution, and distilled water $(590 \mathrm{~mL})$ were transferred into a beaker $(1 \mathrm{~L})$. After a half hour, $1.2 \mathrm{~mL}$ PRAS stock solution was added to the simulative wastewater. Then the $\mathrm{pH}$ of the mixed solution was adjusted to 8.0, followed by the use of the mixing stages for flocculation experiments.

After the first flocculation, the flocs were settled by centrifugation step of $3652 \times g$ (Kaida TG16G, China) for $10 \mathrm{~min}$ and $10 \mathrm{~mL}$ of the clarified layer of solution at a depth of $2 \mathrm{~cm}$ was collected. And then heavy metals in the solutions were determined by AAS. After cleaning and washing the flocs, the reusability of PRAS was studied. The flocs were totally dissolved in $10 \mathrm{~mL}$ water at $\mathrm{pH}$ 1.5. It was ensured that the most of metal ions were released and that the polymer networks were stretched by the protonation of amino groups. PRAS was then regenerated accompanied by increasing elution solution $\mathrm{pH}$ to 3.0. After the removal of regenerated flocculant from the solution by centrifugation. $\mathrm{Cu}$ (II) and $\mathrm{Zn}$ (II) in the supernatant liquid were also determined by AAS. The regenerated flocculant was again tested for further flocculation of metal ions. Flocculation and deflocculation experiments were conducted for four cycles as described above.

\section{Results and discussion}

\subsection{Characterization}

3.1.1. FTIR spectra. Two kinds of samples (DS 0.17 and 0.23 ) were synthesized and used as flocculants throughout the experiment. The FTIR spectra of ST and PRAS with DS $=0.23$ were recorded and shown in Fig. 2. In the spectrum of ST (Fig. 2a), the characteristic peaks at 3437, $2925 \mathrm{~cm}^{-1}$ and a triplet peak at $1154 \mathrm{~cm}^{-1}$ correspond to $\mathrm{O}-\mathrm{H},{ }^{12} \mathrm{C}-\mathrm{H}$ stretching vibrations in the methylene groups, and $\mathrm{C}-\mathrm{O}-\mathrm{C}$ stretching vibration of the glucose rings of $\mathrm{ST},{ }^{29}$ respectively. The wavenumber at $1653 \mathrm{~cm}^{-1}$ was assigned as C-O-C stretching vibrations, while the peaks of $\mathrm{C}-\mathrm{H}$ bending vibrations $\left(1460 \mathrm{~cm}^{-1}\right)$ in the methylene groups of starch was detected. ${ }^{29,30}$ Absorption bands appeared at 1154, 1086 and $1023 \mathrm{~cm}^{-1}$ are the characteristic peaks of the glucose rings of ST. ${ }^{11,31}$

As illustrated in Fig. 2b, the new peaks at 1600, 1425 and $1325 \mathrm{~cm}^{-1}$ can be assigned to the $-\mathrm{COO}^{-}$stretching vibration in PRAS synthesis. ${ }^{31,32}$ The new peak at 1600 and $1425 \mathrm{~cm}^{-1}$ comes 


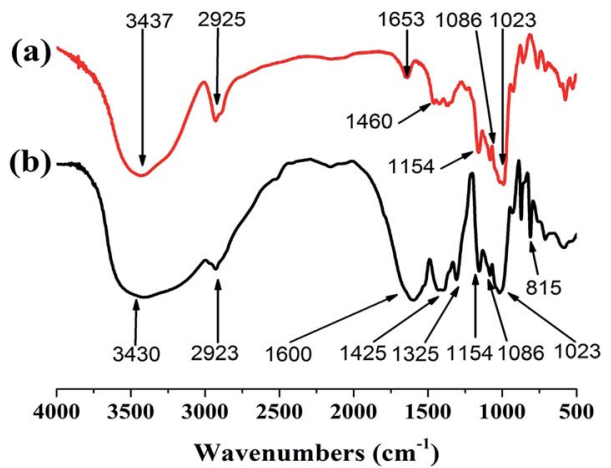

Fig. 2 FTIR spectra of (a) ST and (b) PRAS with DS $=0.17$.

from the stretching vibrations of the $s$-triazine ring in comparison to ST. ${ }^{8,11}$

3.1.2. ${ }^{1} \mathrm{H}$ NMR spectra. ${ }^{1} \mathrm{H}$ NMR spectra of PRAS and the corresponding assignments are shown in Fig. 3 . The proton of the anhydroglucose unit (AGU) in corn starch is readily observed using ${ }^{1} \mathrm{H}$ NMR $\left(\mathrm{NaOD} / \mathrm{D}_{2} \mathrm{O}\right)$. The detailed assignments are as follows: $\delta=5.30[\mathrm{H} 1,(1-4)-\alpha$-linkages $]$, and $\delta=(\mathrm{H} 2-\mathrm{H} 6)$, which is consistent to a previous study ${ }^{33,34}$ The anomeric proton (H1) of the unmodified anhydrous glucose unit (AGU) appeared at $5.20 \mathrm{ppm} .{ }^{35}$ The chemical modification of the AGU then led to a significant shift of the corresponding signals..$^{35}$ Furthermore, proton signals, $\delta=3.80(\mathrm{H} 8)$, at the methylene group of $-\mathrm{CH}_{2}{ }^{-}$ $\mathrm{COO}^{-}$are observed in the ${ }^{1} \mathrm{H}$ NMR spectra. The FTIR and ${ }^{1} \mathrm{H}$ NMR results directly indicate that the CDT moieties are incorporated within the ST network after chemical modification.

\section{2. $\mathrm{pH}$ responsiveness properties of PRAS}

3.2.1. DS-induced phase transition. As shown in Fig. 4a, the changes in transmittance of PRAS were determined based on transmittance measurements at a wavelength of $590 \mathrm{~nm}$ over a range of $\mathrm{pH}$ values from 1 to 8 . The U-shaped curve of PRAS became more obvious with the increase of the degree of substitution (DS). Upon changing DS of PRAS, the ratio of hydrophobic and hydrophilic groups in a polymer chain was changed, which altered the relatively sharp transition of turbidity with $\mathrm{pH}$. As an amphoteric polyelectrolyte, aqueous PRAS solution tends to

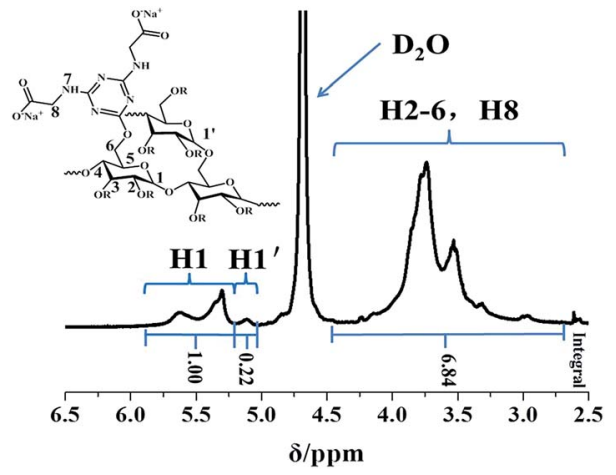

Fig. $3{ }^{1} \mathrm{H}$ NMR spectra of PRAS (DS $=0.17$ ) in deuterated $\mathrm{NaOD} / \mathrm{D}_{2} \mathrm{O}$.

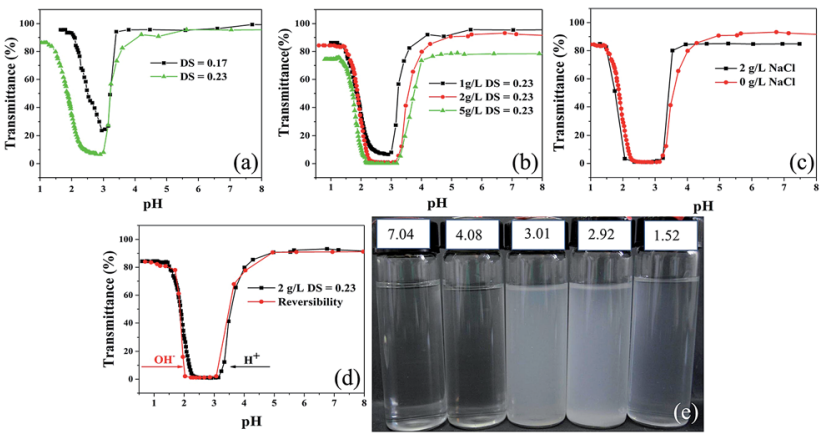

Fig. 4 Transmittance vs. pH of aqueous PRAS under absorbance at $590 \mathrm{~nm}$ for (a) $1 \mathrm{~g} \mathrm{~L}^{-1}$ PRAS aqueous solution with different DS. (b) PRAS (DS $=0.23$ ) at different concentrations. (c) $2 \mathrm{~g} \mathrm{~L}^{-1}$ PRAS (DS $=$ $0.23)$ aqueous solution with different $\mathrm{NaCl}$ concentrations. (d) Reversible phase transition of the $2 \mathrm{~g} \mathrm{~L}^{-1}$ PRAS ( $D S=0.23$ ) aqueous solution by the addition of acid in the black line and base in the red line. (e) Photographs of $1 \mathrm{~g} \mathrm{~L}^{-1}$ PRAS (DS $=0.23$ ) aqueous solution at various $\mathrm{pH}$ values.

precipitate around the isoelectric point (IEP). ${ }^{10,36}$ As for PRAS with DS 0.23 , three relatively sharp $\mathrm{pH}$ phase transitions $(\mathrm{pH} \approx 4.0$, 3.0, and 1.5) were observed during reducing $\mathrm{pH}$ by addition of $\mathrm{HCl}$. When the $\mathrm{pH}$ was higher than 4.5 , the transmittance reached a plateau and kept unchanged owing to the deprotonation of the carboxyl groups. ${ }^{25}$ With the decrease of $\mathrm{pH}$ value from 4.5 to 3.0, the clear solution turned cloudy due to the protonation of hydrophilic carboxyl groups. Further decreasing $\mathrm{pH}$ from 3.0 to 1.5, the turbid solution became clear again, indicating the existence of protonated amine groups.

3.2.2. Concentration-induced phase transition. As shown in Fig. $4 \mathrm{~b}$, the transmittance of PRAS solution decreased with increasing PRAS concentration (DS $=0.23$ ) at the same $\mathrm{pH}$. The $\mathrm{pH}$-responsive properties of PRAS can be described by the critical $\mathrm{pH}\left(\mathrm{pH}^{*}\right)$, at which the transmittance is decreased by $50 \%$ in a manner similar to the lower critical solution temperature (LCST) ${ }^{26,37}$ In Fig. 4 b, the $\mathrm{pH}^{*}$ are 3.7, 3.5, and 3.2 for concentrations of 5.0, 2.0, and $1.0 \mathrm{~g} \mathrm{~L}^{-1}$, respectively. These results indicated that $\mathrm{pH}^{*}$ increased with increasing polymer concentration. Such fact verifies that higher concentration is correlated with some degree of increased interchain interactions and with sufficient polymer aggregate formation at higher $\mathrm{pH}^{38}$

3.2.3. Ionic strength effect on phase transition. The effect of ionic strength was also investigated regarding to the phasetransition behavior of PRAS (DS $=0.23$ ) as shown in Fig. 4c. The U-shaped distribution of PRAS solutions without $\mathrm{NaCl}$ is narrower than that with $2 \mathrm{~g} \mathrm{~L}^{-1} \mathrm{NaCl}$. Upon increasing ionic strength, electrostatic interactions among the protonated carboxyl groups were shielded gradually. Moreover, as has been reported, ${ }^{39}$ water molecules could be polarized by the adjacent anions, leading to weak intermolecular hydrogen bonding. Thus, the hydrodynamic volume and the hydrophilic interaction of the polymer chains decreased ${ }^{40,41}$ As a result of reduction in interactions among PRAS chains, the phase transition became more insensitive to $\mathrm{pH}$ at higher ionic strength.

As shown in Fig. 4d, the pH-induced phase transition was also stable and reversible with addition of $1 \mathrm{M} \mathrm{NaOH}$ or $\mathrm{HCl}$. 
Owing to the $\mathrm{pH}$ responsiveness of PRAS, as-prepared flocculant should be able to selectively capture and release heavy-metal ions from wastewater by adjusting the $\mathrm{pH}$ of the solution.

3.2.4. Reversible phase transition. As was shown in Fig. 4d, the $\mathrm{pH}$-induced and reversible phase transition behavior is stable and reversible with the addition of $1 \mathrm{M} \mathrm{NaOH}$ or $\mathrm{HCl}$ solutions. It is proven that PRAS has reversible phase transition behavior that is based on the data obtained. When PRAS dissolved in the aqueous or in crystal, it was ampholyte that existed as a sort of zwitterions or dipole ionic with different $\mathrm{pH}$. The ionization balance is expressed as follows: ${ }^{42}$

$$
\begin{aligned}
\mathrm{N}^{+} \mathrm{H}_{2}\left(\mathrm{RR}^{\prime}\right) \mathrm{COOH} & \stackrel{\mathrm{OH}^{-}}{\stackrel{\mathrm{H}^{+}}{\rightleftarrows}} \mathrm{NH}\left(\mathrm{RR}^{\prime}\right) \mathrm{COOH} \\
& \stackrel{\mathrm{OH}^{-}}{\rightleftarrows} \mathrm{HH}\left(\mathrm{RR}^{\prime}\right) \mathrm{COO}^{-} .
\end{aligned}
$$

As-prepared flocculant can selectively capture and release heavy metal ion from waste water by adjusting the $\mathrm{pH}$ of solution.

\subsection{Removal of metal(II) from aqueous solution}

3.3.1. pH-dependent removal of metal(II) from water solution. The $\mathrm{pH}$-dependence of zeta potential (ZP) of PRAS (DS $=0.23$ ) was examined as shown in Fig. 5a. PRAS is composed of both cationic and anionic functional groups. The $\mathrm{ZP}-\mathrm{pH}$ profiles indicate that the IEP of PRAS is very close to the midpoint in the $\mathrm{pH}$ range of 1.5 to 4.0 at which the cationic charge just balances the anionic charge on the PRAS. Below $\mathrm{pH}$ 1.5 or above $\mathrm{pH} 4$, the zwitterionic polymer re-dissolved to form a transparent solution. With the increase of the amount of hydroxide ions $(\mathrm{pH})$, the equilibrium shifted to the right, and the $\mathrm{ZP}$ reduced and became negative (Fig. 5a).

The metal-removal efficiency of PRAS solution $\left(50 \mathrm{mg} \mathrm{L}^{-1}\right)$ for $\mathrm{Cu}(\mathrm{II})\left(78 \mathrm{mg} \mathrm{L}^{-1}\right)$ and $\mathrm{Zn}$ (II) $\left(74 \mathrm{mg} \mathrm{L}^{-1}\right)$ at various $\mathrm{pH}$ values is presented in Fig. 5b. Upon increasing $\mathrm{pH}$ of the flocculation solution, the flocculation performance enhanced. The optimum $\mathrm{pH}$ region of PRAS to remove $\mathrm{Cu}$ (II) and $\mathrm{Zn}$ (II) was over 7.0, where the ZP closed to the negative maximum (Fig. 5a). Upon increasing $\mathrm{pH}$ value, the carboxylic groups on the PRAS were progressively deprotonated and reached fully dissociation, while the flocculant was dissolved in water because of the high ionizability of the anionic groups, and formed a more extended conformation. Polymer bridging and charge neutralization took
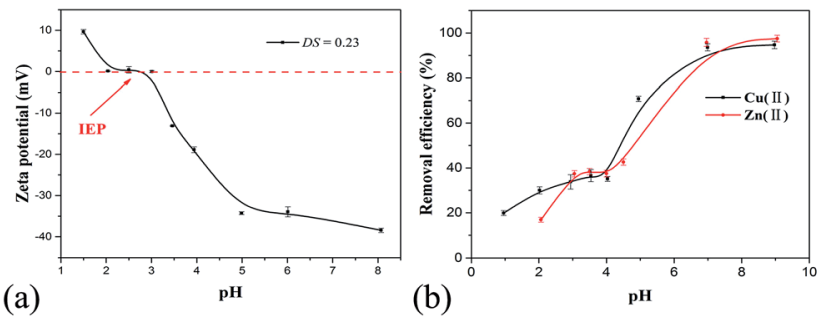

Fig. 5 (a) ZP as a function of $\mathrm{pH}$ for $2 \mathrm{~g} \mathrm{~L}^{-1}$ PRAS (DS $=0.23$ ) solution at $25^{\circ} \mathrm{C}$, and (b) effect of $\mathrm{pH}$ on the removal efficiency of $\mathrm{Cu}\left({ }^{\prime \prime}\right)$ and Zn(II) by PRAS. place between the negatively charged flocculant and heavymetal cation, leading to increased flocculation efficiency. ${ }^{\mathbf{9}, \mathbf{4 3}}$ When $\mathrm{pH}$ value approached to the IEP $(\mathrm{pH}=3.0)$, the flocculant was transformed to insoluble material at this critical $\mathrm{pH}$. At this stage, the ability of charge neutralization was weakened due to the offset of the charges between cationic and anionic functional groups.

3.3.2. Effect of flocculant dosage on flocculation. To determine the optimal PRAS dosage for metal ion removal, the effect of flocculant dosage on flocculation was investigated. Amphoteric starch products with DS of 0.17 and 0.23 were exposed to an aqueous solution containing $78 \mathrm{mg} \mathrm{L}^{-1} \mathrm{Cu}(\mathrm{II})$ and $74 \mathrm{mg} \mathrm{L}{ }^{-1} \mathrm{Zn}$ (II). The results were shown in Fig. 6.

$\mathrm{Zn}$ (II) removal efficiency increased and reached almost $100 \%$ upon increasing the PRAS dosage to $0.07 \mathrm{~g} \mathrm{~L}^{-1}$. At low dosages, the number of anionic charges was insufficient for complete neutralization of the cationic charges of metal ions, resulting in weak destabilization of colloids by the flocculant. The maximum $\mathrm{Zn}$ (II) removal appeared at the amphoteric starch dosages around $0.07 \mathrm{~g} \mathrm{~L}^{-1}$. However, excessive dosage makes the metal particles potentially completely covered by the absorbed polymer layer. Thus, steric repulsion generated well-established particles and resulted in a reduced efficiency., ${ }^{\mathbf{9 4 - 4 6}}$ In addition, PRAS has triazine rings with large $\pi$-electron clouds, which cause an enhanced coordination with metal ions. ${ }^{8}$ For highly substituted amphoteric starch derivative (DS $=0.23$ ), the $\mathrm{Zn}$ (II) removal efficiency became more sensitive to PRAS dosage, and the window for the best $\mathrm{Zn}$ (II) removal efficiency reduced significantly (Fig. 6a). Similar results can be observed in Fig. 6b, which shows the effect of amphoteric starch dosages on $\mathrm{Cu}(\mathrm{II})$ removal.

\subsection{Regeneration of PRAS}

PRAS is a promising flocculant for the removal of $\mathrm{Cu}$ (II) and $\mathrm{Zn}$ (II) from waste water. Owing to the $\mathrm{pH}$ responsiveness of PRAS, the PRAS can be simply regenerated by adjusting the $\mathrm{pH}$ of the elution solution.

The flocs were totally dissolved in water at $\mathrm{pH}$ 1.5. This ensured that the metal ions were almost fully released. Then, PRAS was regenerated by increasing the elution solution $\mathrm{pH}$ to 3.0. After the removal regenerated flocculant from the solution by centrifugation, the solution was analyzed using AAS.

In addition, the stability of the PRAS and the reproducibility of the flocculation properties were also evaluated after several flocculation/regeneration cycles. As shown in Fig. 7, the removal
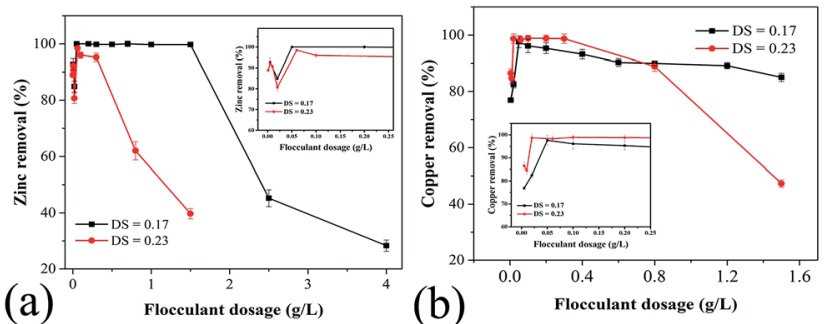

Fig. 6 Effect of PRAS dosage on (a) Zn(॥) and (b) Cu(॥) removal efficiency. The changing parameter is the degree of substitution (DS). 


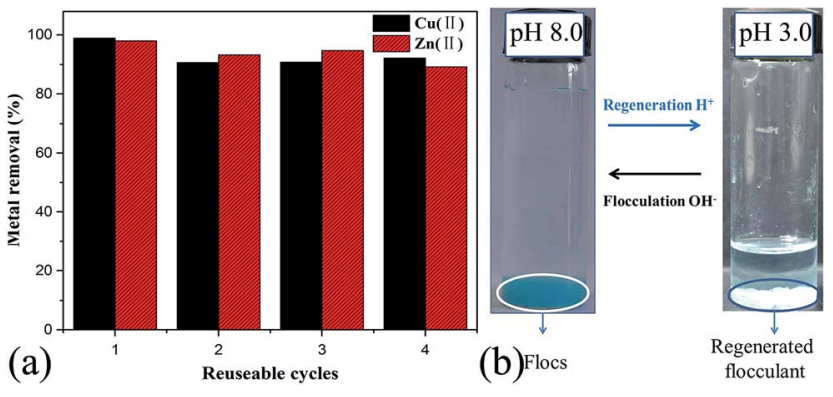

Fig. 7 (a) Metal removal efficiency of PRAS in four successive cycles of flocculation-regeneration. (b) Photographs of regenerated elution of $\mathrm{Cu}(\mathrm{II})$ before and after regeneration by PRAS

efficiency in the fourth cycle was up to $92 \%$ and $89 \%$ for copper and zinc, respectively, which means after three cycles PRAS retained $93 \%$ and $91 \%$ remove rate for $\mathrm{Cu}(\mathrm{II})$ and $\mathrm{Zn}(\mathrm{II})$, respectively. The reuse of PRAS in thus reduced the costs of the overall flocculation process significantly.

\section{Conclusions}

In summary, a novel pH-responsive amphoteric starch derivative (PRAS) bearing dual functional groups (amino and carboxyl groups) was successfully prepared through etherification of starch with 2-chloro-4,6-diglycino-[1,3,5]-triazine (CDT). PRAS exhibited reversible $\mathrm{pH}$-response properties in aqueous solutions. $\mathrm{Cu}$ (II) and $\mathrm{Zn}$ (II) ions can be almost fully removed by PRAS from contaminated water through a flocculation process. Owing to its $\mathrm{pH}$ responsiveness, the subsequent reusability of PRAS could be achieved by adjusting the solution $\mathrm{pH}$. In addition, the stability of the PRAS and the reproducibility of the flocculation properties were also evaluated after several flocculation/regeneration cycles. The results showed that PRAS retained $93 \%$ and $91 \%$ remove rate for $\mathrm{Cu}(\mathrm{II})$ and $\mathrm{Zn}(\mathrm{II})$, respectively, after three cycles.

\section{Conflicts of interest}

There are no conflicts to declare.

\section{Acknowledgements}

We are grateful to The Natural Science Foundation of China (21467024, 51764049 and 21661027), The Found of State Key Laboratory of Mineral Processing (BGRIMM-KJSKL-2015-10), China Postdoctoral Science Foundation (2014M561426), The Project-sponsored by Scientific Research Start-up Fund for High-Level Talents, Shihezi University (KX0138), National Training Programs of Innovation and Entrepreneurship for Undergraduates (201710759054), Transformation of Technological Achievements in Shihezi Unviersity (CGZH201715).

\section{Notes and references}

1 A. Agrawal, S. Kumari and K. K. Sahu, Ind. Eng. Chem. Res., 2009, 48, 6145-6161.
2 A. Ma, P. Hadi, J. Barford, C. W. Hui and G. Mckay, Ind. Eng. Chem. Res., 2014, 53, 13773-13781.

3 H. Wu, R. Yang, R. Li, C. Long, H. Yang and A. Li, Environ. Sci. Pollut. Res., 2015, 22, 13038-13048.

4 F. Fu and Q. Wang, J. Environ. Manage., 2011, 92, 407-418.

5 N. Oyaro, O. Juddy, E. N. M. Murago and E. Gitonga, J. Food, Agric. Environ., 2007, 5, 119-121.

6 A. T. Paulino, F. A. Minasse, M. R. Guilherme, A. V. Reis, E. C. Muniz and J. Nozaki, J. Colloid Interface Sci., 2006, 301, 479-487.

7 J. Huang, H. Xie, H. Ye, T. Xie, Y. Lin, J. Gong, C. Jiang, Y. Wu, S. Liu and Y. Cui, Carbohydr. Polym., 2016, 138, 301-308.

8 S. Jia, Z. Yang, W. Yang, T. Zhang, S. Zhang, X. Yang, Y. Dong, J. Wu and Y. Wang, Chem. Eng. J., 2016, 283, 495-503.

9 H. Peng, S. Zhong, Q. Lin, X. Yao, Z. Liang, M. Yang, G. Yin, Q. Liu and H. He, Carbohydr. Polym., 2016, 138, 210-214.

10 Z. Yang, S. Jia, T. Zhang, N. Zhuo, Y. Dong, W. Yang and Y. Wang, Sep. Purif. Technol., 2015, 149, 398-406.

11 Y. Shi, B. Ju and S. Zhang, Carbohydr. Polym., 2012, 88, 132138.

12 Y. Wang, Y. Shi, M. Xu, L. Wu, X. Jia, T. Wei, S. Zhang and X. Guo, RSC Adv., 2016, 6, 44383-44391.

13 M. C. Koetting, J. T. Peters, S. D. Steichen and N. A. Peppas, Mater. Sci. Eng., R, 2015, 93, 1-49.

14 H. S. Song, O. S. Kwon, J. H. Kim, J. Conde and N. Artzi, Biosens. Bioelectron., 2016, 89, 187-200.

15 M. A. Stuart, W. T. Huck, J. Genzer, M. Müller, C. Ober, M. Stamm, G. B. Sukhorukov, I. Szleifer, V. V. Tsukruk and M. Urban, Nat. Mater., 2010, 9, 101-113.

16 R. A. Lorenzo, A. M. Carro, A. Concheiro and C. AlvarezLorenzo, Anal. Bioanal. Chem., 2015, 407, 4927-4948.

17 Y. Cao, N. Liu, C. Fu, K. Li, L. Tao, L. Feng and Y. Wei, ACS Appl. Mater. Interfaces, 2014, 6, 2026-2030.

18 D. Zhao, L. Liu, L. Yan, X. Yu and G. Guo, ACS Appl. Mater. Interfaces, 2016, 8, 31281-31288.

19 R. Yang, H. Li, M. Huang, H. Yang and A. Li, Water Res., 2016, 95, 59-89.

20 S. Ghosh, G. Sen, U. Jha and S. Pal, Bioresour. Technol., 2010, 101, 9638-9644.

21 C. Y. Teh, P. M. Budiman, K. P. Y. Shak and T. Y. Wu, Ind. Eng. Chem. Res., 2016, 55, 4363-4389.

22 B. Xiang, W. Fan, X. Yi, Z. Wang, F. Gao, Y. Li and H. Gu, Carbohydr. Polym., 2016, 136, 30.

23 S. N. Khattab, S. E. A. Naim, M. Elsayed, A. A. E. Bardan, A. O. Elzoghby, A. A. Bekhit and A. Elfaham, New J. Chem., 2016, 40, 9565-9578.

24 K. H. Kan, J. Li, K. Wijesekera and E. D. Cranston, Biomacromolecules, 2013, 14, 3130-3139.

25 B. H. Tan, P. Ravi and K. C. Tam, Macromol. Rapid Commun., 2006, 27, 522-528.

26 Y. Xu, B. Ju and S. Zhang, Carbohydr. Polym., 2014, 114, 530536.

27 L. Shi, F. Xiong, C. P. Tan, H. Qiang and B. Zhang, J. Agric. Food Chem., 2017, 65, 2189.

28 Q. Wu, R. You, Q. Lv, Y. Xu, W. You and Y. Yan, Chem. Eng. J., 2015, 281, 491-501. 
29 K. Kaewtatip and V. Tanrattanakul, Carbohydr. Polym., 2008, 73, 647-655.

30 E. J. Lee, D. K. Kweon, B. K. Koh and S. T. Lim, J. Appl. Polym. Sci., 2004, 92, 861-866.

31 Q. Jiang, W. Gao, X. Li, Z. Liu, L. Huang and P. Xiao, Starch, 2011, 63, 692-699.

32 T. Spychaj, K. Wilpiszewska and M. Zdanowicz, Starch, 2013, 65, 22-33.

33 J. Bohrisch and A. Zimmermann, Starch, 2010, 59, 208-216.

34 T. Heinze, K. Pfeiffer, T. Liebert and U. Heinze, Starch, 1999, 51, 11-16.

35 B. Ju, D. Yan and S. Zhang, Carbohydr. Polym., 2012, 87, 1404-1409.

36 S. Liu and S. P. Armes, Angew. Chem., Int. Ed., 2002, 41, 14131416.

37 M. Gao, X. Jia, Y. Li, D. Liang and Y. Wei, Macromolecules, 2010, 43, 159-163.
38 X. Jiang, C. Feng, G. Lu and X. Huang, Polymer, 2015, 64, 268-276.

39 Z. Wang, M. Gao, J. Sun, D. Liang and X. Jia, Macromolecules, 2013, 46, 1723-1731.

40 Y. Li, S. Zhang, X. Meng, X. Chen and G. Ren, Carbohydr. Polym., 2011, 83, 130-136.

41 B. Mu, P. Liu, X. Li, P. Du, Y. Dong and Y. Wang, Mol. Pharmaceutics, 2012, 9, 91-101.

42 Y. Zeng, Z. Li and E. Asselin, Ind. Eng. Chem. Res., 2015, 54, 3488-3497.

43 G. Tian, W. Wang, Z. Li, Y. Kang and A. Wang, Chem. Eng. J., 2016, 293, 376-385.

44 Q. Lin, H. Peng, Q. Lin and G. Yin, Water Sci. Technol., 2013, 68, 1352-1358.

45 T. Tripathy and B. Ranjan De, J. Phys. Sci., 2006, 10, 93-127. 46 T. Zhang, M. Wang, W. Yang, Z. Yang, Y. Wang and Z. Gu, Ind. Eng. Chem. Res., 2014, 53, 14913-14920. 